\title{
Willingness of Private Physicians to Be Involved in Smallpox Preparedness and Response Activities
}

\author{
ANNE E. COWAN, PAMELA L. Y. H. CHING, SARAH J. CLARK, and ALEX R. KEMPER
}

Background. The public health system continues its efforts to prepare for bioterrorist events, such as a smallpox outbreak, but may need to call on other health professionals to ensure sufficient capacity to implement preparedness plans.

Objective. The goal was to understand the willingness of primary care physicians to participate in possible smallpox pre- or post-event activities.

Methods. A 23-question mail survey was sent to a national random sample of 727 internists and 720 family physicians. After three mailings, a one-page version of the survey was sent to nonrespondents.

Results. Response rates were $26 \%$ for questions common to both surveys and $22 \%$ for questions on the longer survey only. Respondents to the survey expressed moderate support for participating in certain smallpox pre- and post-event activities. Under a pre-event scenario, many providers would be willing to vaccinate first responders in their practice, and roughly one-third would be willing to vaccinate patients in their practice or to work in a public health clinic as a vaccinator. Most physicians, however, would be unwilling to be vaccinated themselves. Under post-event conditions, most providers would be willing to vaccinate their own patients, and many would vaccinate other community members in their practice.

Conclusions. Despite the low response rate, information from this study on the smallpox preparedness activities in which physicians are most willing to participate can help to inform efforts by public health officials and private physicians to collaborate on bioterrorism preparedness efforts.

\begin{abstract}
A S PART OF THE NATION'S EFFORTS to prepare for potential bioterrorist activities, federal, state, and local governments have been engaged in the National Smallpox Vaccination Program (NSVP) to ensure that the public health system is prepared to respond quickly to a smallpox outbreak. ${ }^{1}$ It is unclear, however, whether the capacity of the public health system to implement various components of the NSVP is sufficient. For example, the national capacity to implement a pre-event smallpox vaccination program for interested members of the general public, a potential component of the NSVP, ${ }^{1}$ has not been assessed. Similarly, the public health system may
\end{abstract}

not have adequate surge capacity to meet demand for vaccination in the event of a smallpox outbreak.

To assure that there is adequate capacity for various smallpox vaccination efforts, public health officials may seek the assistance of other health professionals. Primary care physicians in private practice may be a viable option, given their clinical training in administering vaccines and in recognizing and treating communicable diseases. In addition, research has shown that the majority of adults would seek care from their own physician first, over a hospital emergency room or public health department, if they thought they had smallpox disease. ${ }^{2}$

Anne E. Cowan, MPH; Sarah J. Clark, MPH; and Alex R. Kemper, MD, MPH, MS, are with the Child Health Evaluation and Research (CHEAR) Unit, Division of General Pediatrics, University of Michigan, Ann Arbor. Pamela L.Y.H. Ching, MS, SD, RD, LD, is with the Health Services Research and Evaluation Branch, Immunization Services Division, National Immunization Program, Centers for Disease Control and Prevention, Atlanta, Georgia. 
Little is known about the willingness of private physicians to participate in smallpox vaccination activities. The goal of this study was to explore the knowledge and attitudes of private physicians regarding smallpox and smallpox vaccination and to assess their level of interest in participating in smallpox vaccination efforts under certain pre- and post-outbreak scenarios.

\section{METHODS}

\section{Sample}

The target population for the survey was primary care physicians who provide care to people aged 18 years and older. It was limited to adult care providers because the pre-event vaccination program for the general public that was under consideration at that time, which was a major focus of the survey, was intended only for adults. ${ }^{1}$

A national random sample of 750 internal medicine physicians and 750 family physicians was drawn from the American Medical Association (AMA) Masterfile, a database of all licensed physicians in the United States. The sampling frame included all allopathic and osteopathic physicians in office-based direct patient care whose board certification and self-described primary specialty were internal medicine or family practice. Physicians with a sub-board or secondary specialty listing were excluded. Physicians 70 years of age or older, resident physicians, and physicians practicing at military or federal (e.g., Veterans Administration) facilities also were excluded. The AMA Masterfile sample was reviewed to ensure that the above criteria were met, resulting in the deletion of 53 physicians from the sample. The final sample consisted of 1,447 physicians: 727 internal medicine physicians and 720 family physicians.

\section{Survey Instrument and Administration}

We developed a 23-question survey to explore the willingness of private physicians to participate in preand post-event smallpox vaccination activities; factors associated with such participation; knowledge, attitudes, and beliefs about smallpox vaccination; sources of information regarding smallpox vaccination; and physician demographics and practice characteristics. The survey was pilot-tested for clarity with a random sample of 17 internists and 18 family physicians.

Three mailings of the survey were conducted between May and July 2003. Because the response rate (see the Results section below) was low based on our previous experience with other immunization-related surveys to a similar physician population, ${ }^{3-5}$ we hypothesized that nonresponse was mainly related to the length of the survey or lack of interest in the survey topic. To explore the effect of survey length on the response rate, we developed a one-page version of the survey containing seven of the most critical questions from the original version. The "short" survey focused on the willingness of physicians to participate in various pre-event vaccination activities and on physician demographics and practice characteristics. The one-page version of the survey was mailed in August 2003 to nonrespondents to the original survey.

\section{Analysis}

For analysis purposes, survey responses for the seven questions shared by the original and short versions of the survey were combined and analyzed separately from the remaining 16 questions on the original survey. Frequency distributions were calculated and chi-square tests were used to assess bivariate associations. $P$ values less than 0.05 were considered significant. All analyses were performed using STATA 8.2 (StataCorp, College Station, Tex). This study was approved by the University of Michigan Medical Center Institutional Review Board.

\section{RESULTS}

\section{Response Rate}

Of the 1,447 physicians in the final sample, 54 were ineligible or unable to be contacted. A total of 305 eligible surveys were returned after three mailings for a response rate of $22 \%$. After the mailing of the short survey, 62 surveys were returned. Therefore, the response rate was $26 \%$ for the seven questions common to both surveys and $22 \%$ for the remaining 16 questions on the original survey. Overall response rates by physician specialty were $22 \%$ for internists and $31 \%$ for family physicians $(p \leq$ $0.01)$.

\section{Respondent Demographics and Practice Characteristics}

Respondent demographics and practice characteristics are summarized in Table 1. Almost $60 \%$ of the respondents to both surveys $(N=367)$ were family physicians. Most respondents (74\%) had been vaccinated against smallpox prior to 1980. Almost all (99\%) offer adult vaccines in their practice. For the majority of respondents (56\%), the ownership or affiliation of their primary practice setting is a private, independent office. We compared respondents to the short survey with respondents to the original survey by physician specialty and history of smallpox vaccination prior to 1980 and found no statistically significant differences $(p=0.26$ and $p=0.48$, respectively). 
Table 1. Respondent Demographics and Practice Characteristics for Physician Survey on SMallpox Vaccination

\begin{tabular}{lc}
\hline All Respondents $(N=367)$ & \\
\hline Specialty & $58 \%$ \\
$\quad$ Family practice & $42 \%$ \\
$\quad$ Internal medicine & $74 \%$ \\
Vaccinated against smallpox prior to 1980* & $99 \%$ \\
Practice offers adult vaccines (e.g., influenza) & $56 \%$ \\
Practice ownership/affiliation & $19 \%$ \\
$\quad$ Private, independent office & $10 \%$ \\
$\quad$ Hospital/medical center & $15 \%$ \\
\hline Practice network (including HMOs) & $14 \%$ \\
Other & $24 \%$ \\
\hline Respondents to Original Survey Only ( $n=305)$ & $11(11)$ \\
\hline History of military service (active duty or reserve) & $3(3)$ \\
Contract or volunteer work in public health setting & 48 (95) \\
Years in practice, mean (median) & \\
Number of physicians in practice, mean (median) & \\
Number of patients per week, mean (median) & \\
\hline & $*$ In the U.S., routine smallpox vaccination of the general public ended in 1972; “1980" \\
was used on the survey to allow room for error in respondent recall and to allow for the rare \\
instance of vaccination after 1972.
\end{tabular}

Of respondents to the original survey $(n=305), 14 \%$ had served in the military in some capacity (i.e., active duty or reserve), and almost one-quarter (24\%) had done contract or volunteer work in a public health setting since completion of their residency training. On average, respondents had been in practice 11 years, were in practice with three physicians, and saw 48 patients per week.

\section{Willingness to Participate in Smallpox Pre-event Vaccination Efforts}

Respondents were asked to consider a pre-event scenario in which interested adult members of the general public could voluntarily receive smallpox vaccination. Under this scenario, the majority of respondents (61\%) felt that vaccine should be administered both in a public health setting and a clinical setting versus exclusively in one setting or the other. There was no difference by physician specialty $(p=0.79)$ or by history of smallpox vaccination prior to $1980(p=0.13)$.

Almost a third of respondents (30\%) would be "somewhat willing" or "very willing" to offer smallpox vaccine in their practice to their interested patients. Most (52\%) were "not very willing" or "not at all willing," while $18 \%$ were neutral. There was no difference in respondents' willingness based on physician specialty $(p=0.46)$, history of smallpox vaccination prior to $1980(p=0.23)$, or the version of the survey received (original versus short) $(p=0.42)$.

Respondents to the original version of the survey were asked to assess the degree of influence of five possible concerns related to smallpox disease and smallpox vaccination on their willingness to offer pre-event smallpox vaccination in their practice (Table 2). The probability of a known vaccine adverse event was cited by the largest proportion of respondents (68\%) as being a "strong influence" on their willingness to offer pre-event vaccination in their practice. Other concerns cited as a "strong influence" by the majority of respondents were the risk of a smallpox outbreak (53\%) and the risk of transmission of the smallpox vaccine virus to others (52\%).

Respondents to the original survey also were asked to assess the extent to which any of seven factors would be necessary for them to consider offering smallpox vaccination in their practice (Table 3). The majority of respondents considered all of the factors to be necessary, particularly liability protection (95\%) and guidance on program logistics $(92 \%)$. 
Table 2. Degree of Influence of Smallpox-Related Concerns on Willingness to OfFer Smallpox Vaccination in Practice for Voluntary Pre-Event Smallpox Vaccination of Interested Adults $(n=305)$

\begin{tabular}{lccc}
\hline Concerns & $\begin{array}{c}\text { Strong } \\
\text { influence }\end{array}$ & $\begin{array}{c}\text { Some } \\
\text { influence }\end{array}$ & $\begin{array}{c}\text { No } \\
\text { influence }\end{array}$ \\
\hline $\begin{array}{l}\text { Probability of a known adverse reaction to } \\
\text { vaccination }\end{array}$ & $68 \%$ & $30 \%$ & $2 \%$ \\
$\begin{array}{l}\text { Risk of a smallpox outbreak } \\
\begin{array}{l}\text { Risk of transmission of smallpox vaccine } \\
\quad \text { virus to others }\end{array}\end{array}$ & $53 \%$ & $34 \%$ & $13 \%$ \\
$\begin{array}{l}\text { Possibility of an unknown adverse reaction to } \\
\quad \text { vaccination }\end{array}$ & $35 \%$ & $54 \%$ & $9 \%$ \\
Challenge of screening for contraindications & $33 \%$ & $55 \%$ & $11 \%$ \\
\hline
\end{tabular}

Most respondents (88\%) reported that patient demand would prompt them to consider offering smallpox vaccination in their practice. With respect to certain scenarios related to patient demand, $42 \%$ would be influenced by a "critical number" of patients interested in vaccination, $36 \%$ by a "critical level of insistence" among patients interested in vaccination, and $41 \%$ by lack of another option in the community for patients to be vaccinated.

\section{Willingness to Participate in Other Pre-event Activities}

All respondents were asked whether they would be willing to participate in certain other pre-event vaccination activities, assuming that they would receive training, liability protection, and compensation for their participation, and that capacity within their community to vaccinate interested members of the general public was other- wise insufficient. While the majority of respondents (59\%) would be willing to offer vaccination in their practice to first responders (e.g., police), just over one-quarter would be willing to offer vaccination in their practice to interested members of the community who may not be their patients $(28 \%)$ or to be a vaccinator at a public health clinic (26\%). There were no differences in willingness to participate in one or more of these pre-event vaccination efforts by physician specialty $(p=0.67)$ or by history of smallpox vaccination prior to $1980(p=0.45)$.

In addition to vaccination-related activities, the majority of physicians (68\%) would be "somewhat willing" or "very willing" to evaluate their patients with suspected mild to moderate adverse reactions to smallpox vaccine, regardless of where they received their pre-event vaccination. Another $14 \%$ were neutral, while $18 \%$ would be "not very willing" or "not at all willing." There were no differences based on physician specialty $(p=0.88)$, his-

Table 3. Extent to Which Factors Would Be Necessary to Consider Offering Smallpox Vaccination in Practice for Voluntary Pre-Event Smallpox Vaccination of Interested Adults $(n=305)$

\begin{tabular}{lccc}
\hline Factor & Necessary & $\begin{array}{c}\text { Important but } \\
\text { not necessary }\end{array}$ & $\begin{array}{c}\text { Not } \\
\text { important }\end{array}$ \\
\hline $\begin{array}{l}\text { Liability protection } \\
\text { Guidance on logistics of vaccination administration }\end{array} \quad 95 \%$ & $92 \%$ & $4 \%$ & $1 \%$ \\
$\quad$ and storage & & $8 \%$ & $0 \%$ \\
Reimbursement for vaccine administration & $86 \%$ & $13 \%$ & $1 \%$ \\
On-site training & $76 \%$ & $23 \%$ & $1 \%$ \\
Support of nursing staff & $73 \%$ & $22 \%$ & $5 \%$ \\
Support of health system or practice ownership & $70 \%$ & $21 \%$ & $9 \%$ \\
Willingness of other physicians in the practice & $63 \%$ & $24 \%$ & $13 \%$ \\
\hline
\end{tabular}


tory of smallpox vaccination prior to $1980(p=0.45)$, or the version of the survey received $(p=0.06)$.

\section{Willingness to Receive and Recommend Vaccination}

Less than one-quarter of physicians (22\%) would choose to be vaccinated if their practice were to offer smallpox vaccination, while about one-third (32\%) were unsure. Of respondents who would choose not to be vaccinated (46\%), the main reasons given were contraindications to vaccination (32\%), the belief that vaccination is unnecessary in the absence of an outbreak (18\%), and the belief that the risks of vaccination outweigh the benefits $(15 \%)$. For about $10 \%$ of these respondents, the main reason they would choose not to be vaccinated was that they had been recently vaccinated as a member of a smallpox response team.

If their practice were to offer smallpox vaccination, about one-third of respondents would recommend vaccination to their clinical staff (34\%) or their patients interested in vaccination (33\%), assuming vaccination was not contraindicated. About half of respondents would not recommend for or against vaccination to either group.

\section{Preparation for Responding to a Smallpox Outbreak}

Of respondents to the original survey, more than half (59\%) would be willing to provide contact information for their practice to a federal registry of emergency smallpox vaccinators to facilitate rapid community response to a smallpox outbreak. In preparation for responding to an outbreak, respondents would need training in recognizing smallpox (87\%), vaccine handling and administration (97\%), and recognizing and treating vaccine adverse events (98\%).
Under the scenario that the public health system may not have sufficient capacity to meet the demand for vaccination in the event of a smallpox outbreak, respondents were asked whether they would be willing to participate in certain post-event activities. Almost all (89\%) would be willing to offer vaccination in their practice to their patients, and $82 \%$ would choose to be vaccinated. A majority $(64 \%)$ would be willing to offer vaccination in their practice to members of their community who may not be their patients, while less than half (44\%) would be willing to be a vaccinator at a public health clinic.

\section{Knowledge, Attitudes, and Beliefs Related to Smallpox and Smallpox Vaccine}

Respondents to the original survey were asked to assess the extent to which they agreed with five statements related to smallpox disease and smallpox vaccine (Table 4). Few respondents perceived the risk of an outbreak to be high, with only $13 \%$ agreeing that a smallpox outbreak or attack is likely in the U.S. in the next five years. Differences in the perceived risk of an outbreak did not affect physicians' willingness to offer vaccination in their practice under a pre-event smallpox vaccination program for the general public.

Most, but not all, physicians believed that smallpox vaccine is effective in preventing smallpox disease $(88 \%)$. However, only a third (35\%) believed that the vaccine is safe. Nearly half of the physicians felt that they could recognize the symptoms of smallpox (45\%) and were confident in their knowledge regarding the vaccine $(44 \%)$.

\section{DISCUSSION}

Among the primary care physicians responding to this survey, there was at least moderate support for partici-

Table 4. Knowledge, Attitudes, and Beliefs Regarding Smallpox and Smallpox Vaccine $(n=305)$

\begin{tabular}{lccc}
\hline & Agree & Neutral & Disagree \\
\hline $\begin{array}{l}\text { In the next } 5 \text { years, a smallpox outbreak or attack is } \\
\text { likely in the U.S. }\end{array}$ & $13 \%$ & $26 \%$ & $61 \%$ \\
$\begin{array}{l}\text { Vaccination is effective in preventing smallpox } \\
\text { disease. }\end{array}$ & $88 \%$ & $7 \%$ & $5 \%$ \\
$\begin{array}{l}\text { Overall, the smallpox vaccine is safe. } \\
\text { I am confident in my ability to recognize symptoms } \\
\quad \text { of smallpox. }\end{array}$ & $35 \%$ & $27 \%$ & $38 \%$ \\
$\begin{array}{l}\text { I am confident in my level of knowledge regarding } \\
\text { smallpox vaccine. }\end{array}$ & $44 \%$ & $21 \%$ & $33 \%$ \\
\hline
\end{tabular}


pating in smallpox pre-event vaccination efforts. Many providers would be willing to vaccinate first responders in their practice, and roughly one-third would be willing to vaccinate patients in their practice or work in a public health clinic as a vaccinator.

In addition, these physicians demonstrated a willingness to be involved in post-event activities and to participate in a system to plan for such a contingency. Under post-event conditions, most providers would be willing to vaccinate their own patients, and many would vaccinate other community members in their practice.

There are two main limitations of this study. First, the validity of physicians' predicted behavior based on hypothetical scenarios is unknown. Second, the low response rate limits the generalizability of these findings. Because the response rate for the original survey was low, we hypothesized that nonresponse was mainly related to the length of the survey or lack of interest in the survey topic. We developed the short version of the survey to assess the impact of the first issue; however, the response to the one-page survey did not greatly increase the overall response rate. After the mailing of the short survey, we developed and sent out postcards to 1,016 nonrespondents asking them for the reason or reasons that they did not respond to the survey. Seventy postcards were returned for a response rate of $7 \%$. Out of 89 reasons given for not responding to prior mailings of the survey, the main reasons were that they do not respond to surveys in general $(n=21,24 \%)$, the survey was too long $(n=20,22 \%)$, or they believe the threat of smallpox to be low ( $n=16$, $18 \%)$. An additional $17 \%(n=15)$ said they do not provide patient care or offer vaccines in their practice, and the remainder ( $n=17,19 \%$ ) gave other reasons.

Despite these limitations, the content of the responses received bears some consideration by those interested in bioterrorism preparedness. The results of this study suggest that there is at least a subset of primary care physicians in private practice who would be willing to assist public health officials in their smallpox preparedness and response efforts. Variations in the level of support expressed by physicians in this study, depending on the pre- or post-event scenario being considered, have some implications for how policymakers might best integrate private physicians into their preparedness and response plans, and demonstrate that enlisting the assistance of physicians requires careful discussion and forethought.

Physicians in this study were hesitant about receiving the vaccine themselves in a pre-event scenario. Similar attitudes toward pre-event vaccination have been shown in studies regarding the willingness of physicians to be vaccinated as part of hospital-based smallpox response teams in the first stage of the NSVP ${ }^{6-10}$ and are consistent with low influenza vaccination rates among health-care workers. ${ }^{11}$ In addition, their willingness to be vaccinated may have been influenced by the unexpected occurrence of cardiac-related side effects (i.e., myopericarditis), which were initially documented a few months before the survey was conducted. ${ }^{12}$ Physicians' lack of interest in pre-event vaccination has implications for potential plans for a voluntary, pre-event smallpox vaccination program for the general public. The capacity required to implement such a program would depend in part on the level of interest of the general public in being vaccinated. While the public's interest has previously been shown to be relatively high, it was also greatly influenced by the vaccination decisions of practicing physicians. ${ }^{2}$

Despite physicians' reluctance to be vaccinated, they expressed some willingness to participate in pre-event smallpox activities. For example, private physicians are an option for expanding the capacity to vaccinate first responders, which is the second stage of the NSVP. Public health officials would need to establish contact with the primary care physicians in their community to ascertain who is willing to help and determine how best logistically to incorporate them into vaccination plans.

Private physicians are not as willing to participate in efforts outside of their own practice. Therefore, if there is a need to increase the number of available vaccinators for public health clinics, planners will likely need to consider other health professionals, such as school nurses. ${ }^{13}$

Private physicians are willing to vaccinate their patients in an outbreak scenario. Therefore, public health officials should ensure that these physicians are included in response planning efforts and determine how best to integrate their participation with that of other health professionals (e.g., school nurses, ${ }^{13}$ hospital-based smallpox response teams).

In this survey, as in a prior national survey, ${ }^{14}$ physicians indicated that they would need additional training in order to assist with bioterrorism response efforts. Providing appropriate guidance and training not only helps to assure that physicians feel prepared, but also increases the chance that physicians will be willing to assist with response efforts and that the efforts will be successful. ${ }^{14,15}$

Smallpox preparedness is just one of the many facets of the efforts to upgrade the capabilities of the public health system to prepare for and respond to public health emergencies. The benefits of a collaborative relationship between the public health system and private physicians in bioterrorism preparedness efforts have been clearly shown. ${ }^{15}$ Information from this study on the bioterrorism preparedness activities in which physicians are most willing to participate can help public health officials target their efforts to establish this collaboration. 


\section{REFERENCES}

1. Bush GW. White House press release. December 13, 2002. Protecting Americans: Smallpox Vaccination Program. Available at: http://www.whitehouse.gov/news/releases/ 2002/12/20021213-1.html. Accessed June 8, 2004.

2. Blendon RJ, DesRoches CM, Benson JM, Herrmann MJ, Taylor-Clark K, Weldon KJ. The public and the smallpox threat. N Engl J Med 2003;348(5):426-432.

3. Davis MM, McMahon SR, Santoli JM, Schwartz B, Clark SJ. Physicians' responses to influenza vaccine delays. $J$ Gen Intern Med 2000-01;16(Suppl 1):192.

4. Davis MM, McMahon SR, Santoli JM, Schwartz B, Clark SJ. A national survey of physician practices regarding influenza vaccine. J Gen Intern Med 2002;17(9):670-676.

5. Davis MM, Ndiaye SM, Freed GL, Clark SJ. One-year uptake of pneumococcal conjugate vaccine: a national survey of family physicians and pediatricians. $\underline{J \text { Am Board Fam }}$ Pract 2003;16(5):363-371.

6. Everett WW, Zaoutis TL, Halpern SD, Strom BL, Coffin SE. Preevent vaccination against smallpox: a survey of pediatric emergency health care providers. Pediatr Infect Dis J 2004;23(4):332-337.

7. Benin AL, Dembry L, Shapiro ED, Holmboe ES. Reasons physicians accepted or declined smallpox vaccine, February through April, 2003. J Gen Intern Med 2004;19(1): $85-89$.

8. Yih WK, Lieu TA, Rego VH, et al. Attitudes of healthcare workers in U.S. hospitals regarding smallpox vaccination. BMC Public Health 2003;3(1):20.
9. Everett WW, Coffin SE, Zaoutis T, Halpern SD, Strom BL. Smallpox vaccination: a national survey of emergency health care providers. Acad Emerg Med 2003;10(6):606-611.

10. Kwon N, Raven MC, Chiang WK, Moran GJ, Jui J, Carter RA, Goldfrank L; EMERGEncy ID Net Study Group. Emergency physicians' perspectives on smallpox vaccination. Acad Emerg Med 2003;10(6):599-605.

11. Centers for Disease Control and Prevention. Prevention and control of influenza: recommendations of the Advisory Committee on Immunization Practices (ACIP). MMWR 2004;53(RR06):1-40.

12. Centers for Disease Control and Prevention. Cardiac adverse events following smallpox vaccination-United States, 2003. MMWR 2003;52:248-250.

13. Gullion JS. School nurses as volunteers in a bioterrorism event. Biosecur Bioterror 2004;2(2):112-117.

14. Alexander GC, Wynia MK. Ready and willing? Physicians' sense of preparedness for bioterrorism. Health Affairs 2003;22(5):189-197.

15. Gerberding JL, Hughes JM, Koplan JP. Bioterrorism preparedness and response: clinicians and public health agencies as essential partners. JAMA 2002;287(7):898-899.

Address reprint requests to:

Anne Cowan, MPH

300 North Ingalls, Room 6 E16

Ann Arbor, MI 48109-0456

E-mail: cowana@med.umich.edu 
This article has been cited by:

1. Suzanne R. Hawley, Angelia M. Paschal, Elizabeth Ablah, Theresa St. Romain, Kore Liow, Craig A. Molgaard. 2008. Initial Perspectives from Midwestern Neurologists: Epilepsy Patients' Barriers and Motivators for Seeking Treatment. Epilepsia, ahead of print080219051138748-???. [CrossRef]

2. Suzanne R. Hawley, Angelia M. Paschal, Elizabeth Ablah, Theresa St. Romain, Kore Liow, Craig A. Molgaard. 2007. Initial Perspectives from Midwestern Neurologists: Epilepsy Patients' Barriers and Motivators for Seeking Treatment. Epilepsia 48:10, 1920-1925. [CrossRef]

3. Assistant Professor Charles DiMaggio , Assistant Professor David Markenson, George T. Loo , Irwin Redlener . 2005. The Willingness of U.S. Emergency Medical Technicians to Respond to Terrorist IncidentsThe Willingness of U.S. Emergency Medical Technicians to Respond to Terrorist Incidents. Biosecurity and Bioterrorism 3:4, 331-337. [Abstract] [PDF] [PDF Plus] 